\title{
The diagnosis of a personality disorder increases the likelihood for seropositivity to Toxoplasma gondii in psychiatric patients
}

\author{
Dunja Hinze-Selch ${ }^{1}$, Walter Däubener ${ }^{2}$, Sükran Erdag ${ }^{1}$ and Sibylle Wilms ${ }^{1}$
${ }^{1}$ The Centre for Integrative Psychiatry, Department of Psychiatry and Psychotherapy at the Christian Albrecht University, Niemannsweg 147, D-24105 Kiel, Germany;
${ }^{2}$ Institute for Medical Microbiology and Hospital Hygiene, Heinrich Heine University, Universitätsstrasse 1, D-40225 Düsseldorf, Germany

\begin{abstract}
Individuals serologically positive for the chronic infection with the parasite Toxoplasma gondii (TG) display certain personality traits differently from uninfected individuals. Experimental data in mice demonstrate that TG infection modulates behaviour. However, psychiatric patients with a personality disorder have not yet been investigated systematically. In our sample containing 896 psychiatric inpatients with the primary diagnoses of schizophrenia, major depression, schizoaffective or bipolar disorder and 214 psychiatrically unaffected controls (same geographic region, sampled during same time period) we analysed for effects of the additional diagnosis of a personality disorder in the patients. Psychiatrically, a patient can meet the criteria of a personality disorder additionally to any of the mentioned primary diagnoses. We applied logistic regression and cross-table statistics, separated groups by the presence/absence of a personality disorder (ICD-10) and adjusted for age between groups. We found that among all patients the additional diagnosis of a personality disorder was significantly associated with TG infection. Furthermore, only in the patients with an additional personality disorder medium titre responses (1:16-1:64) were associated with chronic course and high C-reactive protein (CRP) levels whereas high titre response $(>1: 64)$ was associated with a more acute recurrent clinical course. In the older individuals only there was a preponderance of medium titre responses $(1: 16-1: 64)$ among the patients with personality disorder compared to those without and controls. We conclude that TG infection and the host's response to it make a difference for the diagnosis of a personality disorder. Our data support that TG infection can modulate human behaviour and personality traits.
\end{abstract}

Keywords: Toxoplasma gondii, personality disorder, major depression, schizophrenia, serology

More than one decade ago Flegr and Hrdý (1994) reported that individuals with serologically proven infection with Toxoplasma gondii (TG) differ with respect to several personality traits compared to uninfected controls. Recently, there is growing evidence that parasites such as T. gondii indeed can modify human and animal behaviour (e.g. Skallová et al. 2006, Henriquez et al. 2009; for review, Webster and McConkey 2010). Toxoplasma gondii with its complex life cycle and networking with the host's organism interferes with several neurotransmitter systems, such as the serotonin and dopamine systems (Hinze-Selch et al. 2007; for review, Vyas and Sapolsky 2010). A very recent report even demonstrates that $T$. gondii by its own is able to synthesize dopamine (Gaskell et al. 2009). There are numerous reports on Toxoplasma serology and psychiatric diagnoses such as schizophrenia and major depression (for review see Torrey et al. 2007). In our large epidemiologic study we found that TG infection by serology is not more frequent in individuals with schizophrenia or major depression compared to a group of psychiatrically not affected healthy individuals controlled for age and region of provenience but the serological response is more intense in the patients than the controls (Hinze-Selch et al. 2007). So, rather than just having more infected individuals among psychiatric patients as suggested by several other studies (for review see Torrey et al. 2007) the host response towards the parasite might differ between patients and controls and might make a difference in this ubiquitous infection. This view is supported by the more recent data that the interaction between the host immune system, the parasitic activity and neurotransmitter systems might be responsible for the behavioural changes that can be seen even experimentally (e.g. Skallová et al. 2006, Henriquez et al. 2009).

Briefly, TG infection in humans takes place when infectious microcysts, typically in affected undercooked or raw meat, are ingested, or through contamination with infected cat faeces (Tenter et al. 2000). Since the infection is

Address for correspondence: D. Hinze-Selch, Fachklinik St. Marienstift Dammer Berge GmbH, Dammer Str. 4a, D-49434, Neuenkirchen, Germany. Phone: +49-5493-502-150; Fax: +49-5493-502-189; E-mail: dunjahs@hotmail.com 
ubiquitous, the probability of becoming infected increases with age, apart from any particular high risk behaviour, as described before.

When TG infects an organism, it invades various cells (Carruthers and Blackman 2005) and persists intracellularly, including in neurons and glia (Halonen et al. 1996, Fischer et al. 1997, Luder et al. 1999). The host organism is not able to eradicate the infection (Tenter et al. 2000). However, immunocompetent hosts control the chronic infection with a T lymphocyte-driven defence (Filisetti and Candolfi 2004). All immunologic mechanisms involved have not yet been unravelled, but it is known that interferon-gamma (IFN- $\gamma$ ) and the enzyme indoleamine 2,3 dioxygenase (IDO) play a role (Däubener and Hadding 1997, Däubener et al. 2001, Fujigaki et al. 2002, 2003, Oberdorfer et al. 2003). Activated T helper cells secrete IFN- $\gamma$, which induces IDO. This enzyme degrades the tryptophan that is needed for the tachyzoitic phase of TG. Consequently, activated parasites die by tryptophan depletion (Däubener and Hadding 1997). The tryptophan degradation products that accumulate via the kynurenine-pathway (Miller et al. 2004) may result in excess dopaminergic tone. Thus, the host defence system might produce a lack of serotonin and an accumulation of dopaminergic activity. Moreover, as shown just recently, TG by its own might produce dopamine (Gaskell et al. 2009). Psychiatrically, both neurotransmitter systems are not only involved in depressive and psychotic syndromes but also in behaviour such as motivation, addiction, aggression, anxiety (Leyton et al. 2000, Moreno et al. 2000, Widner et al. 2002, Booij et al. 2003). Therefore, this parasitic chronic infection, which shifts between silent and microactivated states (Hoff and Carruthers 2002) in conjunction with the host defence system, presents an attractive theoretical schema also for the diagnosis and symptomatology of personality disorders.

Whereas personality traits have been investigated intensely in healthy and psychiatrically not affected individuals, the diagnoses of a personality disorder and the infection with TG have not yet been studied.

We hypothesize that 1) the host response to TG infection is different between psychiatric patients with and without personality disorders, 2) there are associations between the psychiatric main diagnoses and the additional diagnosis of a personality disorder and TG infection and 3 ) there are risk factors for a personality disorder in psychiatric patients. We therefore took advantage of our large epidemiologic study and also analysed our patients by the presence or absence of a personality disorder.

\section{MATERIALS AND METHODS}

All patients who were admitted to inpatient units of our department between 2002 and 2005 and who were diagnosed clinically with schizophrenia, major depression, schizoaffective disorder or bipolar disorder were analysed for their serotitres to TG infection from blood drawn routinely at admission (includ- ing analysis of C-reactive protein [CRP] and leukocyte count; leukocyte count data were not further analysed for the study). The patients were also rated by experienced psychiatrists (S.W. and S.E.) for the course of the disorder $(n=869)$ for schizophrenia, depression, schizoaffective and bipolar disorder by an arbitrary rating scale, with 0 for first episode, 1 for recurrent course, and 2 for chronic course. In addition, the patients were asked to complete a short questionnaire on risky eating habits (now or ever consuming raw or undercooked meat at least several times) and close and risky cat contacts (now or ever cat ownership, cat in the same household, playing closely with cats, cleaning cat litters). When a patient was discharged, the same experienced psychiatrists analysed the patient's records of the admission and all records, if any, of prior admissions. Diagnoses, including those of personality disorders, were assigned according to ICD10 (WHO 1993) using ICD-10 checklists (Hiller et al. 1995) on the basis of the interpretation of the information in the patients' records by the experienced psychiatrists. Basically, any of the 896 patients with the diagnoses of schizophrenia, major depression, bipolar or affective disorder had the chance to meet the diagnosis of one of the subcategories of the diagnosis of a personality disorder. Patients with acute or chronic infectious or inflammatory processes otherwise specified and with any major medical problems involving the immune system were excluded. Nonpsychiatrically affected controls $(n=214)$ were recruited from the same geographic region as the patients who are admitted to our department, which provides regional sectorized psychiatric care. The controls had blood drawn for TG serology, and they completed the questionnaires on risk behaviour. They were screened for psychiatric disorders and major medical problems as well as for present or recent history of infection or inflammation. This study was approved by the local Ethics Committee of the Faculty of Medicine at the Christian-Albrechts-University Kiel. All participants gave informed consent to take part in the study. The data with respect to the diagnoses of schizophrenia and major depression have already been published (Hinze-Selch et al. 2007) and are not reanalysed within these groups in the present study.

TG serology was done by a microbiologist (W.D.) using the internationally established and widely used Toxo-Spot IF (bioMerieux, Lyon, France) according to the instruction of the supplier. Conventionally, for the detection of acute TG infections, the titres are defined as follows: $<1: 16$ negative, no infection; 1:16-1:256 positive immune reaction suggestive of chronic infection; $>1: 256$ positive immune reaction suggestive of recent infection. However, we were interested in differentiating low and high titres in our subjects on the basis of microbiological and immunological expertise. Thus, we collated the individual serotitres as follows: $<1: 16$ no contact with TG; 1:16-1:64 TG contact, low titre response; and $\geq 1: 128$ TG contact, intense individual antibody reaction, high titre response.

For statistical analysis, we used logistic regression by first step and then cross-tables (SPSS for Windows 11.0). In order to test whether certain additional variables had an impact on our results, we tested these variables by cross-tables with our variables of interest. If there were no significant results, we assumed that the additional variables did not have a significant effect on our results. The level of significance (two-tailed) was set at $p \leq 0.05$, statistical trends are reported at $p \leq 0.1$. No adjustment of the error probabilities for multiple testing was performed, because of the explorative nature of the study. 


\section{RESULTS}

\section{Basic characterisation of the patient and controls groups}

We included 277 patients with schizophrenia (age $37.4 \pm 12.0$ years [range 18.7-92.1]), 465 with major depression (age 46.0 \pm 15.5 years [range 18.2-92.3]), 67 with schizoaffective disorder (age 39.7 \pm 12.7 years [range 19.4-72.4]) and 87 with bipolar disorder (age 46.3 \pm 14.0 years [range 18.9-81.2]), in addition 214 healthy controls (age 38.9 \pm 13.3 years [range 18.4-72.7]). Among all patients there were 136 with the additional diagnosis of a personality disorder (age $36.9 \pm 12.9$ years [range 19.1 72.8]; ICD-10: F61.0 with 40\%, F60.3 with 23\%, F60.0 with $0.9 \%$, F60.1 with $1.8 \%$, F60.2 with $2.7 \%$, F60.4 with $3.6 \%$, F60.5 with $2.7 \%$, F60.6 with $5.4 \%$, F60.7 with $8.1 \%$, F60.8 with $7.2 \%$, F60.9 with $4.5 \%$ ). For statistical reasons, the larger the numbers per cell the more difficult becomes the matching for one variable between the cells. Therefore, it is not possible to age-match all the groups in our study. However, in order to deal with microbiologically relevant age effects with respect to TG serology in the between-group analyses we split all statistical analysis at the age of 45 years because this is a turning point in TG serofrequency in our control group (Fig. 1). In the individuals 45 years or younger serofrequency of TG infection ranges between 20 and $40 \%$ without any systematic age effect whereas in the individuals older than 45 years serofrequency systematically increases with age from about 40 to almost $100 \%$. Later on, the cross-table results are reported separately for these two age groups. With the analysis by logistic regression, we used age as continuous variable when appropriate.

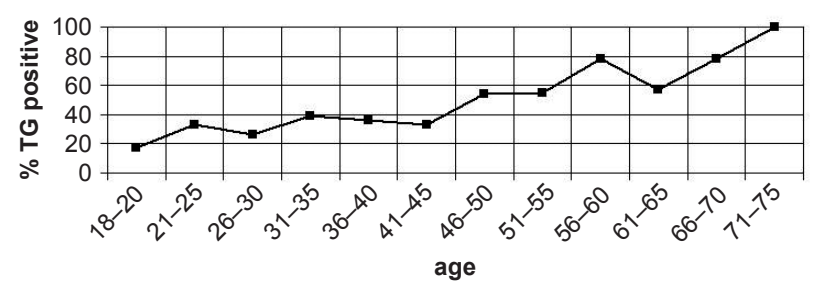

Fig. 1. Percentage of TG positive subjects among all controls depending on age.

\section{The whole dataset by regression analysis}

When we analysed the whole dataset for the discrimination factor of TG seropositive versus seronegative we found that in the TG seropositive individuals there were significantly more individuals older than 45 years and significantly more individuals reporting the consumption of raw or undercooked meat whereas there were no significant effects for all of the remaining variables (Tables 1 and 2). When we analysed for the discrimination factor of patients versus the controls there were no significant effects for all variables but one: cat contact that
Table 1. All patients and controls for the discriminating factor of TG seropositive vs. seronegative.

\begin{tabular}{|c|c|c|c|}
\hline Variables & $\begin{array}{l}\text { Odds } \\
\text { ratio }\end{array}$ & $\begin{array}{l}95 \% \text { Confi- } \\
\text { dence Interval }\end{array}$ & $\begin{array}{c}P \\
\text { I Value }\end{array}$ \\
\hline \multicolumn{4}{|l|}{ Age } \\
\hline Continuous & 1.051 & $1.037-1.066$ & $<.001$ \\
\hline \multicolumn{4}{|l|}{ Sex $($ reference category $=$ Male $)$} \\
\hline Female & 0.883 & $0.618-1.262$ & .494 \\
\hline \multicolumn{4}{|l|}{$\begin{array}{l}\text { Contact with raw meat } \\
\text { (reference category }=\text { Raw meat }- \text { ) }\end{array}$} \\
\hline Raw meat + & 1.655 & $1.155-2.372$ & .006 \\
\hline \multicolumn{4}{|l|}{$\begin{array}{l}\text { Contact with cats } \\
(\text { reference category }=\text { Cats }- \text { ) }\end{array}$} \\
\hline Cats + & 1.219 & $0.842-1.766$ & .294 \\
\hline \multicolumn{4}{|l|}{$\begin{array}{l}\text { Cigarette smoking } \\
(\text { reference category }=\text { Smoking }- \text { ) }\end{array}$} \\
\hline Smoking + & 1.312 & $0.888-.938$ & .173 \\
\hline \multicolumn{4}{|l|}{$\begin{array}{l}\text { One of the major } 4 \text { diagnoses } \\
\text { (reference category = no diagnosis) }\end{array}$} \\
\hline One of the four diagnoses + & 0.868 & $0.718-1.050$ & .145 \\
\hline \multicolumn{4}{|c|}{$\begin{array}{l}\text { Additional diagnosis of a personal disorder } \\
\text { (reference category = no PD) }\end{array}$} \\
\hline \multicolumn{4}{|l|}{$\mathbf{C R P}($ reference category $=<6[\mathrm{mg} / 1])$} \\
\hline$\geq 6[\mathrm{mg} / \mathrm{l}]$ & 1.595 & $1.009-2.521$ & .046 \\
\hline
\end{tabular}

Logistic regression analysis in all patients and controls for the effect of TG infection; odds ratios indicate whether seropositivity for TG increases (odds ratio $>1.0$ ) or decreases (odds ratio $<1.0$ ) the probability for the variable as listed in the first column of the table.

was increased in the patients. This association was not significant in the univariate cross table analysis (Table 3).

When we analysed among all patients for the discriminating effect of the additional diagnosis of a personality disorder we found that the additional diagnosis of a personality disorder was significantly associated with increased likelihood of TG infection and younger age (Table 4). Cigarette smoking just failed the statistical trend.

\section{Further analyses by chi-square statistics}

We found that among the patients with personality disorder there were significantly more younger than 45 years, and this was comparable to the age distribution within the controls, but different from the patients without personality disorder $(76 \%$ and $73 \%$ versus $57 \%, \mathrm{p}<0.001)$. The cigarette smokers were significantly more frequent among the patients with personality disorder than those without and the controls ( $72 \%$ versus $57 \%$ versus $32 \%$, $\mathrm{p}<0.001$ ). The clinical course was significantly more often severe and chronic in those with personality disorder compared to those without $(58 \%$ versus $35 \%, \mathrm{p}<0.001)$. We then analysed for the intensity of the serological response to $\mathrm{TG}$ and seroresponse per se. We found that in the whole group there were no differences. However, when we split the groups by the age of 45 years we found that in the individuals older than 45 years there were at least trend effects: there were more consumers of raw meat among those with an additional personality disorder compared to those without and the controls (Table 5) and those with 
Table 2. All patients and controls for the discriminating factor of TG seropositive vs. seronegative by cross-tables in detail, consequent analysis from Table 1.

\begin{tabular}{|c|c|c|c|}
\hline Variables & $\begin{array}{l}\text { TG-seroposi- } \\
\text { tive }(45.8 \%)\end{array}$ & $\begin{array}{l}\text { TG-seronega- } \\
\text { tive }(54.2 \%)\end{array}$ & $\begin{array}{l}\text { - All patients } \\
\text { and controls }\end{array}$ \\
\hline Age $* * *$ & $\%$ & $\%$ & $\%$ \\
\hline$\leq 45$ & 47.3 & 75.2 & 62.4 \\
\hline$>45$ & 52.7 & 24.8 & 37.6 \\
\hline Sex & $\%$ & $\%$ & $\%$ \\
\hline Male & 45.1 & 42.2 & 43.6 \\
\hline Female & 54.9 & 57.8 & 56.4 \\
\hline Contact with raw meat * & $\%$ & $\%$ & $\%$ \\
\hline Raw meat + & 60.3 & 48.5 & 54.0 \\
\hline Raw meat - & 39.7 & 51.5 & 46.0 \\
\hline Contact with cats & $\%$ & $\%$ & $\%$ \\
\hline Cats + & 63.0 & 60.0 & 61.4 \\
\hline Cats - & 37.0 & 40.0 & 38.6 \\
\hline Cigarette smoking & $\%$ & $\%$ & $\%$ \\
\hline Smoking + & 58.8 & 57.2 & 58.0 \\
\hline Smoking - & 41.2 & 42.8 & 42.0 \\
\hline CRP & $\%$ & $\%$ & $\%$ \\
\hline$<6[\mathrm{mg} / \mathrm{l}]$ & 76.9 & 84.9 & 81.1 \\
\hline$\geq 6[\mathrm{mg} / \mathrm{l}]$ & 23.1 & 15.1 & 18.9 \\
\hline Patient and control groups & $\%$ & $\%$ & $\%$ \\
\hline Psychiatrically affected & 83.0 & 79.6 & 76.1 \\
\hline Healthy controls & 17.0 & 20.4 & 23.9 \\
\hline Diagnoses of patient group & $\%$ & $\%$ & $\%$ \\
\hline Major depression & 57.8 & 46.7 & 51.9 \\
\hline Bipolar disorder & 9.8 & 9.7 & 9.7 \\
\hline Schizophrenia & 26.0 & 35.4 & 30.9 \\
\hline Schizoaffective disorder & 6.4 & 8.2 & 7.5 \\
\hline $\begin{array}{l}\text { Additional diagnosis of } \\
\text { a personal disorder }\end{array}$ & $\%$ & $\%$ & $\%$ \\
\hline $\mathrm{PD}+$ & 17.9 & 16.2 & 15.2 \\
\hline $\mathrm{PD}-$ & 82.1 & 83.8 & 84.8 \\
\hline
\end{tabular}

Consequent cross-table statistics from Table 1 in all patients and controls $(n=1110)$ for the discriminating factor of TG seropositive vs. seronegative by the variables as mentioned in the table; $* \mathrm{p}<0.05, * * *$ $\mathrm{p}<0.001$. The columns "TG-seropositive" and TG-seronegative" present the percentages from cross-table analyses and refer to the asterisk in the column "variables"; column "All patients and controls" presents the distribution of the variables in all patients and controls for general information.

Table 3. Results of logistic regression: odds ratios for independent variables in association with psychiatrically affection (patients and controls).

\begin{tabular}{lccc}
\hline Variables & $\begin{array}{c}\text { Odds } \\
\text { ratio }\end{array}$ & $\begin{array}{c}95 \% \text { Confi- } \\
\text { dence Interval }\end{array}$ & $P$ Value \\
\hline $\begin{array}{l}\text { Age } \\
\begin{array}{l}\text { Continuous } \\
\text { Sex }(\text { reference category = Male) }\end{array}\end{array}$ & 1,028 & $1.016-1.041$ & .000 \\
$\begin{array}{l}\text { Female } \\
\text { Contact with raw meat } \\
\text { (reference category = Raw meat }- \text { ) }\end{array}$ & 0.963 & $0.700-1.324$ & .815 \\
$\begin{array}{l}\text { Raw meat }+ \\
\text { Contact with cats } \\
\text { (reference category }=\text { Cats }- \text { ) }\end{array}$ & 1.053 & $0.763-1.453$ & .754 \\
$\begin{array}{l}\text { Cats }+ \\
\text { TG-infection } \\
(\text { reference category }=\text { TG- infection }- \text { ) }\end{array}$ & 1.408 & $1.015-1.954$ & .041 \\
\begin{tabular}{l} 
TG-infection + \\
\hline
\end{tabular} & 1.039 & $0.743-1.453$ & .821 \\
\hline
\end{tabular}

Logistic regression analysis in all patients and controls for the effect of a patient status; odds ratios indicate whether the patient status increases (odds ratio $>1.0$ ) or decreases (odds ratio $<1.0$ ) the probability for the variable as listed in the first column of the table.
Table 4. All patients analysed for the effect of the additional diagnosis of a personality disorder.

\begin{tabular}{|c|c|c|c|}
\hline Variables & $\begin{array}{l}\text { Odds } \\
\text { ratio }\end{array}$ & $\begin{array}{l}95 \% \text { Confi- } \\
\text { dence Interval }\end{array}$ & $P$ Value \\
\hline \multicolumn{4}{|l|}{ Age } \\
\hline Continuous & 0.961 & $0.943-0.979$ & $<.001$ \\
\hline \multicolumn{4}{|l|}{ Sex (reference category = Male) } \\
\hline Female & 1.207 & $0.774-1.883$ & .407 \\
\hline \multicolumn{4}{|l|}{$\begin{array}{l}\text { Contact with raw meat } \\
\text { (reference category = Raw meat }- \text { ) }\end{array}$} \\
\hline Raw meat + & 0.867 & $0.554-1.358$ & .534 \\
\hline \multicolumn{4}{|l|}{$\begin{array}{l}\text { Contact with cats } \\
(\text { reference category }=\text { Cats }- \text { ) }\end{array}$} \\
\hline Cats + & 1.065 & $0.670-1.695$ & .790 \\
\hline \multicolumn{4}{|l|}{$\begin{array}{l}\text { Cigarette smoking } \\
(\text { reference category }=\text { Smoking }- \text { ) }\end{array}$} \\
\hline Smoking + & 1.453 & $0.896-2.356$ & .129 \\
\hline \multicolumn{4}{|l|}{$\begin{array}{l}\text { TG-infection } \\
\text { (reference category = TG- infection }- \text { ) }\end{array}$} \\
\hline TG-infection + & 1.904 & $1.196-3.029$ & .007 \\
\hline \multicolumn{4}{|l|}{$\mathbf{C R P}$ (reference category $=<6[\mathrm{mg} / \mathrm{l}]$ ) } \\
\hline$\geq 6[\mathrm{mg} / \mathrm{l}]$ & 0.825 & $0.491-1.370$ & .458 \\
\hline
\end{tabular}

Logistic regression analysis in all patients for the effect of the additional diagnosis of a personality disorder; odds ratios indicate whether the additional diagnosis of a personality disorder increases (odds ratio $>1.0$ ) or decreases (odds ratio $<1.0$ ) the probability for the variable as listed in the first column of the table.

Table 5. All patients and controls older than 45 years.

\begin{tabular}{lccc}
\hline & $\begin{array}{c}\text { With PD } \\
\mathrm{n}=33 \\
\%\end{array}$ & $\begin{array}{c}\text { Without PD } \\
\mathrm{n}=291\end{array}$ & $\begin{array}{c}\text { Controls } \\
\mathrm{n}=55\end{array}$ \\
& $\%$ & 60 & $\%$ \\
\hline Raw meat + & 72 & 40 & 52 \\
Raw meat - & 28 & 35 & 35 \\
Titre $<16$ & 24 & 52 & 58 \\
Titre $16-64$ & 67 & 13 & 7 \\
Titre $>64$ & 9 & \\
\hline
\end{tabular}

Chi-square test on eating habits by both patients' and the control groups: $\mathrm{p}=0.09$ with statistical trend interrelationships between consumption of raw meat and the additional diagnosis of a personality disorder.

Chi-square test on serointensity by both patients' and the control groups: $\mathrm{p}=0.1$ with statistical trend interrelationships between medium titre response and the additional diagnosis of a personality disorder.

$\mathrm{PD}=$ personality disorder.

Table 6. All patients with an additional personality disorder.

\begin{tabular}{|c|c|c|c|}
\hline & $\begin{array}{c}\text { Titre }<16 \\
\mathrm{n}=66 \\
\%\end{array}$ & $\begin{array}{c}\text { Titre } 16-64 \\
\mathrm{n}=55 \\
\%\end{array}$ & $\begin{array}{c}\text { Titre }>64 \\
\mathrm{n}=15 \\
\%\end{array}$ \\
\hline $\mathrm{CRP}<6[\mathrm{mg} / \mathrm{l}]$ & 88 & 75 & 93 \\
\hline $\mathrm{CRP} \geq 6[\mathrm{mg} / \mathrm{l}]$ & 12 & 25 & 7 \\
\hline Clinical course acute & 14 & 13 & 0 \\
\hline Clinical course recurrent & 32 & 20 & 62 \\
\hline Clinical course chronic & 54 & 67 & 38 \\
\hline
\end{tabular}

Chi-square test on CRP levels by serointensity: $p=0.1$ with statistical trend interrelationships between increased CRP levels and medium titres.

Chi-square test on the clinical course by serointensity: $p=0.04$ with significant interrelationships between high titre response and recurrent clinical course as well as between medium titre response and chronic clinical course.

$\mathrm{CRP}=\mathrm{C}$-Reactive Protein, cut-off levels between normal and increased at $6 \mathrm{mg} / 1$. 
an additional personality disorder were more likely for medium titre responses (Table 5). Whereas with the more specific TG parameters there were trend effects with the older patients only, effects on gender, smoking habit and clinical course were more distinct within the younger patients: among the patients with a personality disorder there were significantly more females (67\% versus $51 \%$ versus $51 \%, \mathrm{p}=0.05)$, more smokers $(79 \%$ versus $66 \%$ versus $33 \%, \mathrm{p}=0.02)$ and more often a severe and chronic course $(57 \%$ versus $32 \%, \mathrm{p}<0.001)$.

We then analysed separately the patients with and those without an additional personality disorder for interactions of the parameters. In the patients with an additional personality disorder we found that medium titres were associated with high CRP levels as well as chronic course whereas high titres were associated with a more acute recurrent course (Table 6). This was different in the patients without a personality disorder; there was no such association (data not shown). Among the patients with an additional personality disorder there were more females among the seronegative individuals (73\% versus $53 \%$ and $53 \%$ among medium and high titres, $\mathrm{p}=0.05$ ) and more medium titre patients older than 45 years $(41 \%$ versus $12 \%$ and $20 \%$ in the seronegatives and high titre patients, $\mathrm{p}=0.001$ ) but this latter association was also seen in the patients without an additional personality disorder. Finally, among the patients without a personality disorder the seropositive individuals were more likely for the consumption of raw meat $(66 \%$ and $61 \%$ versus $50 \%$ in the seronegatives, $\mathrm{p}=0.002)$.

\section{DISCUSSION}

Taking advantage from our large epidemiologic study in almost 900 psychiatric patients and more than 200 controls we found that the additional diagnosis of a personality disorder makes a difference for the host's response to Toxoplasma gondii (TG) infection. The additional diagnosis of a personality disorder is associated with increased likelihood for TG infection. Moreover, only in the patients with an additional personality disorder high titres were associated with a more acute and recurrent course whereas medium titres went along with a chronic course and increased CRP levels. Among all psychiatric patients the additional diagnosis of a personality disorder is associated with an increased likelihood of TG infection.

High titre response and an acute and relapsing course are suggestive of acutely active or reactivated TG infection. Pathophysiologically, the interactions of TG with critical neurotransmitter systems per se and mediated by the immune system might play a role as described in more detail in the introduction section. Basically, on the one hand, TG can interact with the kynurenine pathway via IDO leading to a dysbalance of metabolites for the dopamine and serotonin system (Däubener et al. 2001, Miller et al. 2004) and on the other hand, TG by itself can synthesize dopamine (Gaskell et al. 2009). Imbalanced serotonin and dopamine systems might mediate key symptoms of personality disorders, in particular affective and motivational symptoms (New et al. 2008). Personality disorders basically are characterized by imbalance, emotionally, cognitively, socially and behaviourally. Recently, there are various publications on certain neuropsychological constructs, such as self-regulation, impulse control and social desirability, on their biological basis and their role in specific personality disorders (DeYoung et al. 2006, Bell and Deater-Deckard 2007, Strüber et al. 2008, Perlman et al. 2009, Cervenka et al. 2010). The complex dopamine system plays a role as well as the serotonin system. From a different perspective, Flegr and his group have gathered similar results. They first found that there were significant peculiarities in the personalities of individuals infected with TG (Flegr and Hrdý 1994). In the meantime there is a profound body of literature supporting that the chronic infection with TG, clinically estimated as asymptomatic, differentially modulates human behaviour (Flegr et al. 2000, Skallová et al. 2005, Lindová et al. 2006, Kolbekova et al. 2007, Henriquez et al. 2009). In addition, there are supporting experimental data in mice (e.g. Skallová et al. 2006, Kannan et al. 2010). Thus, it is likely that chronic TG infection is indeed not clinically asymptomatic. This is supported by our data because we found different associations between TG serology and the additional diagnosis of a personality disorder and no personality disorder. Moreover, in our epidemiologic study on schizophrenia and major depression we found similar associations in the group of schizophrenic patients (Hinze-Selch et al. 2007). First episode was significantly associated with high titres and high titres with high CRP levels; high titre responses might point to a more acute TG activity and host response to it than do low titre responses. Individuals with more intense immune response might labilise their neurotransmitter systems and themselves whereas those individuals with less intense immune responses might be more prone to fixate their symptoms in chronic courses (Hinze-Selch et al. 2007). So, we indeed believe that there are interactions between the host's response to TG and psychiatric symptoms.

However, our data are superficial only with respect to unravelling the underlying mechanisms (Fekadu et al. 2010). There are various genotypes in the dopamine and serotonin system, and there are differences between these genotypes and the behavioural outcome in response to stimuli such as TG infection (e.g. DeYoung et al. 2006, Kannan et al. 2010). Moreover, the immune response to TG also differs between individuals and this might influence the behavioural response, as well (e.g. Hinze-Selch et al. 2007, Henriquez et al. 2009).

Our study demonstrated clear statistically significant association between the diagnosis of a personality disorder and TG infection. However, we can not answer whether 
it is TG infection triggering personality disorder or it is personality disorder facilitating TG infection. There are arguments for both options. The data demonstrating that TG infection can modulate behaviour (e.g. Skallová et al. 2005) support the first mentioned hypothesis. Even if our data do not show any significant effect of our variables "cat contact" and "consumption of raw meat" with respect to the additional diagnosis of a personality disorder, the complexity of personality disorders and the distinct alterations in behaviour in these patients might also trigger TG infection.

The preponderance of females among the patients with an additional personality disorder in our patients points to a specialty of our patients and another possible shortcoming that needs to be mentioned. Offering special inpatient treatment for females with a borderline personality disorder, our group of patients with a personality disorder might not be representative for any personality disorders as a whole. This is reflected also in the preponderance of borderline personality disorder with $23 \%$ and combined personality disorder with $40 \%$ in our patients. As behavioural effects of TG infection might differ by gender (e.g. Lindová et al. 2006, 2010, James 2010) the preponderance of females in our patients needs to be kept in mind when discussing the data even if we did not find gender effects between the diagnostic groups in our data. Furthermore, as mentioned in the beginning, we were not able to further characterize the patients with additional personality disorder for their particular personality traits. For clinical practice reasons in doing this study using clinical routines we had to use ICD-10 and were not able to recur on DSMIV (APA 1994). Therefore, we cannot use the clustering of personality diagnoses that probably might further differentiate our data. However, even then personality disorder is more complex and needs more detailed research. So, our study must remain with the categories of presence or absence of an additional personality disorder in conjunction with the diagnoses of schizophrenia, schizoaffective, bipolar or depressive disorder.

However, even in the light of these specialties and shortcomings we feel that our data are of interest and support the majority of studies reporting associations between personality traits, personality and TG infection and serological host response. Further research is needed. Our study encourages to extent the research on personality traits and TG infection to individuals with a personality disorder.

Acknowledgements. This study was supported by grant No. 01T-404 of The Stanley Medical Research Institute; we would like to thank for this generous support. We appreciate the excellent technical support by Susanne Kell, Imke Petersen, Helga Dittmer and Wilfried Schwippert. We would like to thank Elfriede Fritzer, MA, and Claire Bergmann, RN, for their statistical expertise. Last but not least, we thank all our probands in this study.

\section{REFERENCES}

APA, American Psychiatric Association 1994: Diagnostic and Statistical Manual of Mental Disorders, Fourth Edition. APA, Washington D.C.

Bell M.A., Deater-Deckard K. 2007: Biological systems and the development of self-regulation: integrating behavior, genetics, and pathophysiology. J. Dev. Behav. Pediatr. 28: 409-420.

Booij L., Van der Does A.J., Riedel W.J. 2003: Monoamine depletion in psychiatric and healthy populations: review. Mol. Psychiat. 8: 951-973.

Carruthers V.B., Blackman M.J. 2005: A new release on life: emerging concepts in proteolysis and parasite invasion. Mol. Microbiol. 55: 1617-1630.

Cervenka S., Gustavsson J.P., Halldin C., Farde L. 2010: Association between striatal and extrastriatal dopamine D2-receptor binding and social desirability. NeuroImage 50: 323-328.

Däubener W., Hadding U. 1997: Cellular immune reactions directed against Toxoplasma gondii with special emphasis on the central nervous system. Med. Microbiol. Immunol. (Berl.) 185: 195-206.

Däubener W., Spors B., Hucke C., Rüdiger A., Stins M., Kim K.S., Schroten H. 2001: Restriction of Toxoplasma gondii growth in human brain microvascular endothelial cells by activation of indoleamine 2,3-dioxygenase. Infect. Immun. 69: 6527-6531.

DeYoung C.G., Peterson J.B., Seguin J.R., Mejia J.M., Pihl R.O., Beitchman J.H., Jain U., Tremblay R.E., Kennedy J.L., Palmour R.M. 2006: The dopamine D4 receptor gene and moderation of the association between externalizing behavior and IQ. Arch. Gen. Psychiat. 63: 1410-1416.

Fekadu A., Shibre T., Cleare A.J. 2010: Toxoplasmosis as a cause for behaviour disorders - overview of evidence and mechanisms. Folia Parasitol. 57: 105-113.

Filisetti D., Candolfi E. 2004: Immune response to Toxoplasma gondii. Ann. Ist. Super. Sanita 40: 71-80.

Fischer H.G., Nitzgen B., Reichmann G., Gross U., Hadding U. 1997: Host cells of Toxoplasma gondii encystation in infected primary culture from mouse brain. Parasitol. Res. 83: 637-641.

Flegr J., Hrdý I. 1994: Influence of chronic toxoplasmosis on some human personality factors. Folia Parasitol. 41: 122-126.

Flegr J., Kodym P., Tolarová V. 2000: Correlation of duration of latent Toxoplasma gondii infection with personality changes in women. Biol. Psychol. 53: 57-68.

Fujigaki S., Saito K., Takemura M., Maekawa N., Yamada Y. Wada H., Seishima M. 2002: L-tryptophan-L-kynurenine pathway metabolism accelerated by Toxoplasma gondii infection is abolished in gamma interferon-gene-deficient mice: cross-regulation between inducible nitric oxide synthase and indoleamine-2,3-dioxygenase. Infect. Immun. 70: 779-786.

Fujigaki S., Takemura M., Hamakawa H., Seishima M., Saito K. 2003: The mechanism of interferon-gamma induced anti Toxoplasma gondii by indoleamine 2,3-dioxygenase and/or inducible nitric oxide synthase vary among tissues. Adv. Exp. Med. Biol. 527: 97-103. 
Gaskell E.A., Smith J.E., Pinney J.W., Westhead D.R., McCoNKEY G.A.2009: A unique dual activity amino acid hydroxylase in Toxoplasma gondii. PLoS ONE 4: e4801.

Halonen S.K., Lyman W.D., Chiu F.C. 1996: Growth and development of Toxoplasma gondii in human neurons and astrocytes. J. Neuropathol. Exp. Neurol. 55: 1150-1156.

Henriquez S.A., Brett R., Alexander J., Pratt J., Roberts C.W. 2009: Neuropsychiatric disease and Toxoplasma gondii infection. Neuroimmunomodulation 16: 122-133.

Hiller W., Zaudig M., Mombour W. 1995: Internationale Diagnosen Checklisten für ICD-10 und DSM-IV. Verlag Hans Huber, Bern, Göttingen, Toronto, Seattle, 1. Ed., 127 pp.

Hinze-Selch D., Däubener W., Eggert L., Erdag S., StoltenBERG R., WiLms S. 2007: A controlled prospective study of Toxoplasma gondii infection in individuals with schizophrenia: Beyond seroprevalence. Schiz. Bull. 33: 782-788.

Hoff E.F., Carruthers V.B. 2002: Is Toxoplasma egress the first step in invasion? Trends Parasitol. 18: 251-255.

JAmes W.H. 2010: Potential solutions to problems posed by the offspring sex ratios of people with parasitic and viral infections. Folia Parasitol. 57: 114-120.

Kannan G., Moldovan K., Xiao J.-C., Yolken R.H., JonesBrando L., Pletnikov M.V. 2010: Toxoplasma gondii straindependent effects on mouse behaviour. Folia Parasitol. 57: 151-155.

Kolbekova P., Kourbatova E., Novotna M., Kodym P., Flegr J. 2007: New and old risk-factors for Toxoplasma gondii infection: prospective cross-sectional study among military personnel in the Czech Republic. Clin. Microbiol. Infect. 13: 1012-1017.

Leyton M., Ghadirian A.M., Young S.N., Palmour R.M., Blier P., Helmers K.F., Benkelfat C. 2000: Depressive relapse following acute tryptophan depletion in patients with major depressive disorder. J. Psychopharmacol. 14: 284-287.

Lindová J., Kuběna A.A., Šturcová H., KŘivohlavá R., Novotná M., Rubešová A., Havlíček J., Kodym P., Flegr J. 2010: Pattern of money allocation in experimental games supports the stress hypothesis of gender differences in Toxoplasma gondii-induced behavioural changes. Folia Parasitol. 57: 136-142.

Lindová J., Novotná M., Havlíček J., Jozífková E., Skallová A., Kolbeková P., Hodný Z., Kodym P., Flegr J. 2006: Gender differences in behavioural changes induced by latent toxoplasmosis. Int. J. Parasitol. 36: 1485-1492.

Luder C.G., Giraldo-Velasquez M., Sendtner M., Gross U. 1999: Toxoplasma gondii in primary rat CNS cells: differential contribution of neurons, astrocytes, and microglial cells for the intracerebral development and stage differentiation. Exp. Parasitol. 93: 23-32.

Received 11 January 2010
Miller C.L., Llenos I.C., Dulay J.R., Barillo M.M., Yolken R.H., WEIS S. 2004: Expression of the kynurenine pathway enzyme tryptophan 2,3-dioxygenase is increased in the frontal cortex of individuals with schizophrenia. Neurobiol. Dis. 15: 618-629.

Moreno F.A., Heninger G.R., McGahuey C.A., Delgado P.L. 2000: Tryptophan depletion and risk of depression relapse: a prospective study of tryptophan depletion as a potential predictor of depressive episodes. Biol. Psychiat. 48: 327-329.

New A.S. Goodman M., Triebwasser J., Siever L.J. 2008: Recent advances in the biological study of personality disorders. Psychiatr. Clin. North Am. 31: 441-461.

Oberdorfer C., Adams O., MacKenzie C.R., De Groot C.J., DÄUBENER W. 2003: Role of IDO activation in anti-microbial defense in human native astrocytes. Adv. Exp. Med. Biol. 527: $15-26$.

Perlman S.B., Morris J.P., Vander Wyk B.C., Green S.R., Doyle J.L., Pelphrey K.A. 2009: Individual differences in personality predict how people look at faces. PLoS ONE 22: e5952.

Skallová A., Novotná M., Kolbeková P., Gašová Z., Veselý V., Sechovská M., Flegr J. 2005: Decreased level of novelty seeking in blood donors infected with Toxoplasma. Neuroendocrinol. Lett. 26: 480-486.

Skallová A., Kodym P., Frynta D., Flegr J. 2006: The role of dopamine in Toxoplasma-induced behavioural alterations in mice: an ethological and ethopharmacological study. Parasitology 133: $525-535$.

Strüber D., Lück M., Roth G. 2008: Sex, aggression and impulse control: an integrative account. Neurocase 14: 93-121.

Tenter A.M., Heckeroth A.R., Weiss L.M. 2000: Toxoplasma gondii: from animals to humans. Int. J. Parasitol. 30: 1217-1258.

Torrey E.F., Bartko J.J., Lun Z.R., Yolken R.H. 2007: Antibodies to Toxoplasma gondii in patients with schizophrenia: a meta-analysis. Schiz. Bull. 33: 729-736.

Vyas A., SAPOLSKy R. 2010: Manipulation of host behaviour by Toxoplasma gondii: what is the minimum a proposed proximate mechanism should explain? Folia Parasitol. 57: 8894.

WHO 1993: Mental and behavioural disorders. Diagnostic criteria for research. In: Tenth Revision of the International Classification of Diseases, F-diagnoses.

Webster J.P., McConkey G.A. 2010: Toxoplasma gondii-altered host behaviour: clues as to mechanism of action. Folia Parasitologica 57: 95-104.

Widner B., Laich A., Sperner-Unterweger B., Ledochowski M., Fuchs D. 2002: Neopterin production, tryptophan degradation, and mental depression - what is the link? Brain Behav. Immun. 16: 590-595.

Accepted 30 April 2010 